Article

\title{
Graphite and Solid Fraction Evolutions during Solidification of Nodular Cast Irons
}

\author{
Amaia Natxiondo ${ }^{1}$, Ramón Suárez ${ }^{1}$, Jon Sertucha ${ }^{2}$ and Pello Larrañaga ${ }^{2, *}$
}

1 Veigalan Estudio 2010, Durango E-48200, Spain; E-Mails: anatxiondo@veigalan.com (A.N.); rsuarez@veigalan.com (R.S.)

2 Engineering, R\&D and Metallurgical Processes Department, IK4-Azterlan, Durango E-48200, Spain; E-Mail: jsertucha@azterlan.es

* Author to whom correspondence should be addressed; E-Mail: plarranaga@azterlan.es; Tel.: +34-946-215-470.

Academic Editor: Hugo Lopez

Received: 8 January 2015 / Accepted: 14 February 2015 / Published: 25 February 2015

\begin{abstract}
Ductile iron casting production is strongly affected by austenite and graphite distribution obtained after the solidification process. At the same time it is accepted that solidification behavior can be considered as hypo-, hyper- or eutectic depending on the chemical composition; there is still some misconception about the growth evolution of graphite nodules and about solid fraction progression. Quenching experiments were performed on two different carbon equivalent compositions using inoculated and non-inoculated thermal analysis standard samples with the aim of freezing the existing phases at different solid fractions for each alloy. As a result of these experiments, it was possible to study the structural features found at different locations of each sample and at different stages of solidification. Additionally nodule evolution during the liquid-solid transformation was also analyzed and discussed regarding the chemical and processing characteristics of the prepared alloys.
\end{abstract}

Keywords: solidification; ductile irons; quenching experiments; graphite nodules; solid fraction; austenite 


\section{Introduction}

Ductile iron solidification is a complex process in which the mechanisms that occur during the mushy zone development have not yet been fully mastered [1]. A proper understanding of solid fraction evolution, regarding graphite and austenite nucleation and growth, together with the corresponding contraction-expansion phenomena is of special interest in order to establish the most appropriate industrial procedure to manufacture sound castings and to avoid the formation of shrinkage defects [2]. However this task is not easy as there are a wide variety of solidification possibilities for a given chemical composition. Room temperature samples are commonly available for metallographic characterization but they only show minor traces of graphite and austenite developments during solidification.

Attempts to obtain suitable modeling of the solidification process have been a challenge for a while. One of the first approaches to quantitatively explain and to obtain a feasible structure of cast iron solidification was done by Oldfield as early as 1966 [3]. The quenching experiments performed at that time were then adapted and repeatedly used with the aim to freeze the structural changes that occur under specific conditions and to determine their evolution during solidification. In addition to these aspects quenching methods have been also used to validate the mathematical and thermodynamic bases applied to develop the obtained solidification models. In this way several methodologies have been used to quench cast iron samples. The most used one is to keep the samples in a furnace device equipped with a cooling holder below the furnace. Thus samples are dropped at different temperatures into the quenching liquid [4,5]. This methodology has two main advantages: full temperature control of the samples just before quenching is possible and is highly reproducible. Other researchers quenched different samples during the solidification process by immersing them in water [6,7]. This method is a laborious work that requires good coordination efforts and has significant difficulties in reproducing the experiment exactly at the desired solid fraction. More advanced quenching procedures have also been reported in the literature such as the one where portions of melt are extracted using a quartz tube in order to obtain different solid fractions in the same sample [8].

Regarding information obtained from quenching experiments, various goals were achieved by this technique such as the detection of the graphite branching process and its relationship with modifying elements to form nodules [9], the study of the growing process in different graphite particle shapes [10] (mainly in nodules and compacted particles), the determination of chemical element distribution in the solidifying alloys [11] and effective segregation coefficients [8] as primary solid can easily be detected on quenched samples. Other quenching studies showed how inoculation affected the equiaxial solidification evolution [6] or permitted the quantification of the precipitated phases and related them to Fourier Thermal Analysis [4].

Quenching methodologies can be used to deepen phase transformation knowledge. Previous examples of similar topics are the analysis of microstructural evolution during solidification [12] and during the solid transformation of two ductile iron alloys made by Guo and Stefanescu [5] as well as the primary study performed by the authors on solidification in both ductile and gray iron alloys with different carbon equivalent contents and inoculation conditions [7,13]. In the present work, a detailed study of solid fraction, graphite area fraction and nodule count evolutions during solidification of four ductile cast irons with different chemical and inoculation conditions was approached in combination with the thermal characterization of these alloys. 


\section{Experimental Section}

All samples studied in the present work were obtained from two different cast iron alloys whose chemical compositions are shown in Table 1. Carbon content is determined by combustion technique (and is in good agreement with the one obtained by the thermal analysis system, referred to as $\mathrm{C}_{\mathrm{AT}}$ in Table 2), silicon by gravimetric method and the rest of the elements by Inductively Coupled Plasma (ICP) (Perkin Elmer Optima 5300V, Shelton, CT, USA). The accuracy of each element according to the methodology used is given in brackets for each element in the table.

Table 1. Chemical composition of the prepared cast irons (wt.\%).

\begin{tabular}{|c|c|c|c|c|c|c|c|}
\hline Alloy & $\mathrm{C}(\mathbf{0 . 0 6 )}$ & Si (0.02) & $C E *(0.07)$ & Mn (0.01) & $P(0.004)$ & $S(0.001)$ & $\mathrm{Cr}(0.002)$ \\
\hline A & 3.20 & 2.33 & 3.98 & 0.18 & $<0.015$ & 0.010 & 0.04 \\
\hline B & 3.53 & 2.66 & 4.42 & 0.21 & 0.017 & 0.008 & 0.06 \\
\hline Alloy & Mo (0.002) & $\mathrm{Ni}(0.007)$ & $\mathrm{Cu}(0.005)$ & $\operatorname{Mg}(0.004)$ & Al (0.004) & Ti (0.002) & $\operatorname{Sn}(0.003)$ \\
\hline A & $<0.01$ & 0.04 & 0.03 & 0.045 & 0.010 & 0.016 & $<0.005$ \\
\hline B & $<0.01$ & 0.06 & 0.03 & 0.047 & 0.010 & 0.014 & $<0.005$ \\
\hline
\end{tabular}

* Carbon equivalent calculated as $\mathrm{CE}=\mathrm{C}+\mathrm{Si} / 3$.

Melts were prepared in a $100 \mathrm{~kg}$ medium frequency induction furnace $(250 \mathrm{~Hz}, 100 \mathrm{~kW})$ where metallic charges composed of $37 \%$ cast iron returns, $27 \%$ low alloyed steel scrap, and $36 \%$ low alloyed pig iron were introduced. Particular amounts of a commercial graphite $(\mathrm{C}=98.9 \mathrm{wt} . \%, \mathrm{~S}=0.03 \mathrm{wt} . \%)$ and of FeSi alloy $(\mathrm{Si}=74.6 \mathrm{wt} . \%, \mathrm{Ca}=0.3 \mathrm{wt} . \%, \mathrm{Al}=0.7 \mathrm{wt} . \%)$ were also added to metallic charges so as to approach the designed carbon and silicon contents in the prepared base alloys. After melting, the composition was checked and finally adjusted according to the required contents of these two elements. Then the melt temperature was increased to $1510-1520^{\circ} \mathrm{C}$ and its surface was skimmed before being transferred to a $50 \mathrm{~kg}$ capacity ladle for nodularization treatment with $0.55 \mathrm{~kg}(1.1 \mathrm{wt} . \%$ of the batch weight) of a FeSiMg alloy (grain size 2-20 mm, $\mathrm{Si}=43.54$ wt.\%, $\mathrm{Mg}=5.96$ wt.\%, $\mathrm{Ca}=0.95$ wt.\%, $\mathrm{Al}=0.48$ wt. $\%$ and $\mathrm{RE}=1.08$ wt. $\%$ ) by the sandwich method. The FeSiMg alloy was positioned at the bottom of the ladle and then covered with steel scrap (grain size 5-15 $\mathrm{mm}$ ) before tapping the melt from the furnace. The treatment temperature was in the range $1470-1495{ }^{\circ} \mathrm{C}$.

Four different series each one composed of five thermal analysis (TA) standard cups with a K-type thermocouple located at the center of them were previously placed close to the nodulization treatment area. These TA cups are $35 \mathrm{~mm} \times 35 \mathrm{~mm}$ (average) in horizontal section while their height varies from 37 to $39 \mathrm{~mm}$, giving a geometric modulus in the range of $0.61-0.63 \mathrm{~cm}$ (final weight variation from 330-350 g). In two series denoted as A1 and B1, $0.7 \mathrm{~g}(0.20 \mathrm{wt} . \%$ of the sample weight $)$ of a commercial inoculant (grain size $0.2-0.5 \mathrm{~mm}, \mathrm{Si}=69.9 \mathrm{wt} \%, \mathrm{Al}=0.93 \mathrm{wt} . \%, \mathrm{Ca}=1.38 \mathrm{wt} . \%, \mathrm{Bi}=0.49$ wt.\% and $\mathrm{RE}=0.37 \mathrm{wt} . \%$ ) were added to all cups to obtain the inoculated samples. The other two series were denoted as A2 and B2 and contained plain cups for obtaining the non-inoculated samples. All TA cups were connected to the Thermolan system [2] to record the corresponding cooling curves and then to obtain the most relevant thermal parameters from each one.

After completion of the Mg-treatment reaction for each batch, a sample was taken in order to determine its chemical composition (see Table 1 where the contribution of the inoculation carried out in the $\mathrm{A} 1$ and $\mathrm{B} 1$ series has not been included) and successive samples were then taken by rapidly pouring 
the five TA cups of the corresponding series. In each of these series four samples were successively quenched by introducing them into a cold water tank $\left(10-15^{\circ} \mathrm{C}\right)$ while one of the samples was retained in the TA cup holder to record the whole cooling curve. All quenched samples were vigorously shaken when introducing them into the water bath in order to promote effective quenching of the samples. After cooling to room temperature all the samples were vertically cut in half and one of the newly obtained entire surfaces was prepared for metallographic examination. The surfaces were divided into twelve areas as shown in Figure 1 to evaluate the effect of the quenching process on them. Optical microscopy observations were carried out in these areas in order to estimate the solid fraction ( $\mathrm{f}_{\mathrm{S}}$ ), graphite area fraction $\left(\mathrm{f}_{\mathrm{GA}}\right)$ and nodule count $(\mathrm{N})$ values using commercial image analysis software.

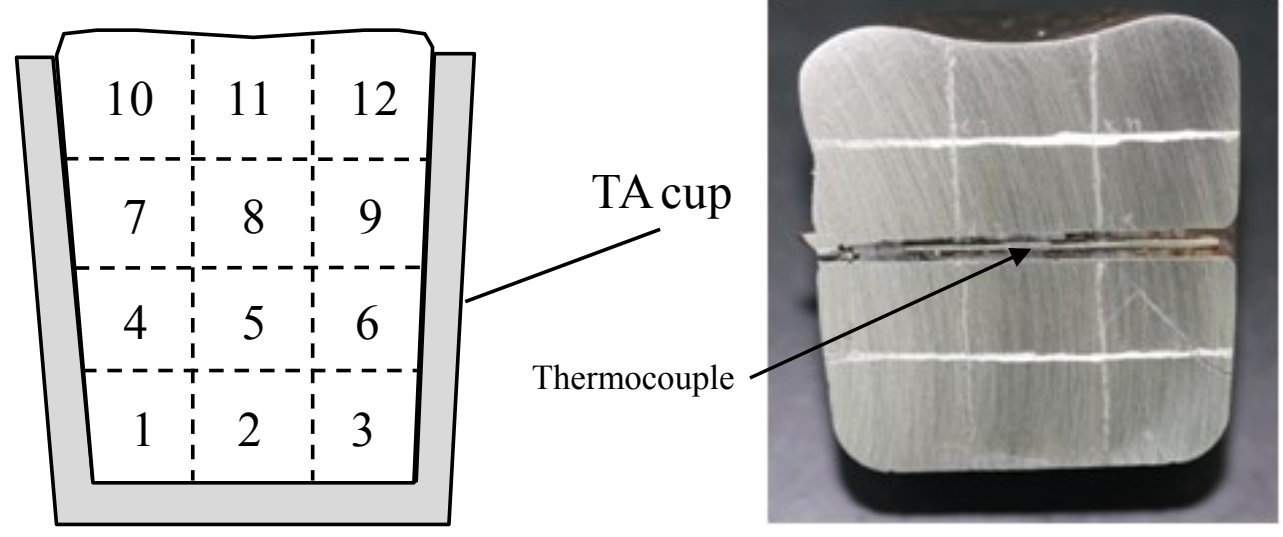

Figure 1. Fields distribution of thermal analysis (TA) samples made for metallographic analyses.

Solid fraction values were determined after etching the surfaces with Nital-5 etchant. The criteria adopted for analyzing all the structures obtained was previously explained in reference [7], i.e., those areas occupied by carbides and martensite were respectively considered as former liquid and austenite regions before quenching effect. Nodule count and $\mathrm{f}_{\mathrm{GA}}$ values were determined on these surfaces without etching.

\section{Results and Discussion}

\subsection{Thermal Characterization of Cast Irons and Quenching Process}

Thermal characterization made on the two cast iron alloys led to the record of the four cooling curves plotted in Figure 2. These records correspond to the non-quenched samples with and without inoculant addition in the TA cup for each composition. The most relevant data obtained from the recorded cooling curves are included in Table 2 according to reference [2]. It can be observed that solidification starts at higher temperatures for the A cast irons than for the $\mathrm{B}$ ones, which can be easily recognized by higher liquidus temperature values $\left(T_{\text {liq }}\right)$. While A alloy shows a clear hypo-eutectic behavior, B alloys, considered as hyper-eutectic by chemical composition, show a slightly hypo-eutectic behavior according to their solidification model. 


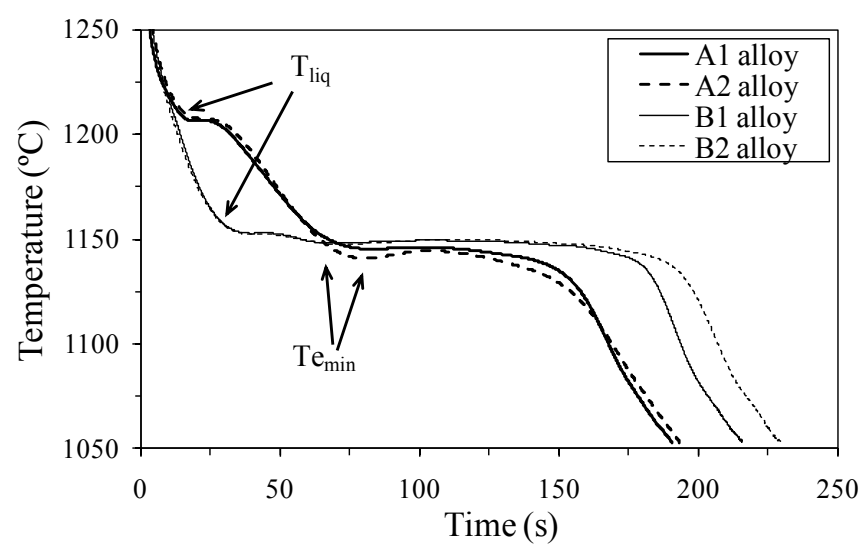

Figure 2. Cooling curves recorded from inoculated and non-inoculated samples.

Table 2. Thermal analysis (TA) parameters obtained from the cooling curves plotted in Figure 2.

\begin{tabular}{ccccccc}
\hline Alloy & Inoculation & $\boldsymbol{T}_{\text {liq }}\left({ }^{\circ} \mathbf{C}\right)$ & $\boldsymbol{T e}_{\min }\left({ }^{\circ} \mathbf{C}\right)$ & $\mathbf{R c}\left({ }^{\circ} \mathbf{C}\right)$ & $\boldsymbol{T}_{\text {sol }}\left({ }^{\circ} \mathbf{C}\right)$ & $\mathbf{C}_{\mathrm{AT}}(\mathbf{\%})$ \\
\hline A1 & yes & 1206.4 & 1145.3 & 0.9 & 1102.4 & \multirow{2}{*}{3.20} \\
A2 & no & 1207.5 & 1140.9 & 3.6 & 1097.5 & \\
\hline B1 & yes & 1152.8 & 1148.0 & 1.5 & 1107.6 & \multirow{2}{*}{3.52} \\
B2 & no & 1152.4 & 1147.7 & 2.1 & 1102.1 & \\
\hline
\end{tabular}

Bulk eutectic reaction, where the massive austenite-graphite precipitation and growth take place, starts at lower temperatures for the A alloys, assessed by lower minimum eutectic temperature $\left(T \mathrm{e}_{\min }\right)$. Inoculation effects only seem to be observed on the bulk eutectic areas as the graphite nodule precipitation must be accelerated from the beginning of this period and consequently lower recalescence $\left(R c=T \mathrm{e}_{\max }-T \mathrm{e}_{\min }\right)$ values are detected. Additionally inoculation effects become less relevant for the A cast irons due to the nucleation promoter effect of high carbon and silicon contents in these alloys. These results are in good agreement with the ones previously reported by the authors for ductile irons [7] and for gray cast irons [13].

Figure 3 shows the different time steps when quenching experiments were primarily carried out for each of the four alloys studied in this work. Note that quenching effectiveness strongly depends on the fast cooling applied to each sample so that deviations between the steps illustrated in Figure 3 and by the corresponding fs values, metallographically obtained, are possible. On the other hand it is necessary here to draw to attention that the A22, A24, B21 and B22 samples were discharged due to the appearance of pearlite in the metallic matrix after quenching which is associated to lack of achievement of sufficient cooling rate during the experiment. Although the quenching process is quite useful, unfortunately its methodology is not similarly efficient in all fields of a given sample. Moreover low quenching efficiencies are expected to be more important in those fields that are less exposed to quenching media, i.e., \#1 to \#6 or the internal ones (see Figure 1). As a consequence it becomes very convenient here to analyze the quenching method effectiveness by means of $\mathrm{fs}$ evolution with all fields present in each sample. 


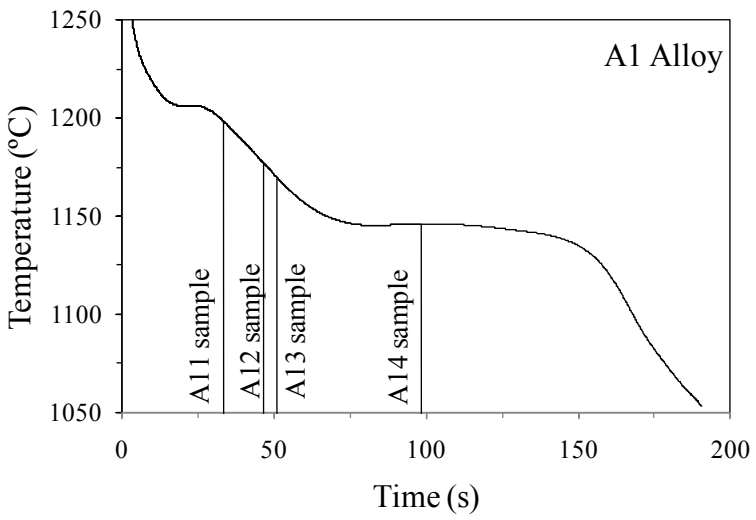

(a)

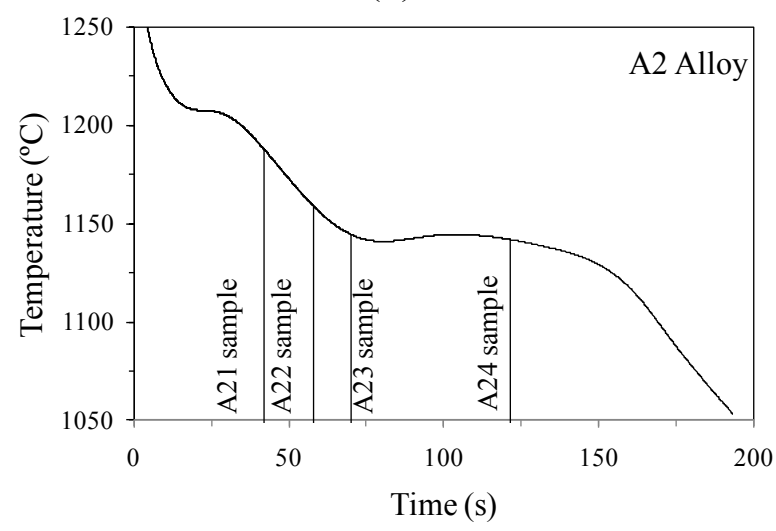

(c)

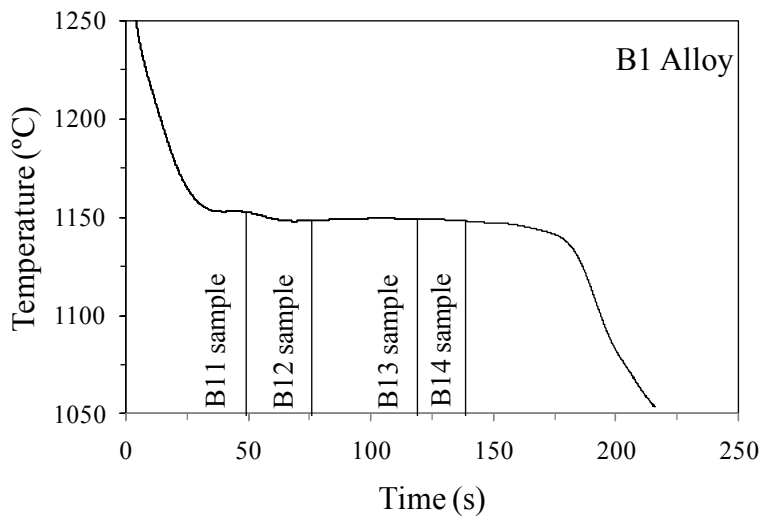

(b)

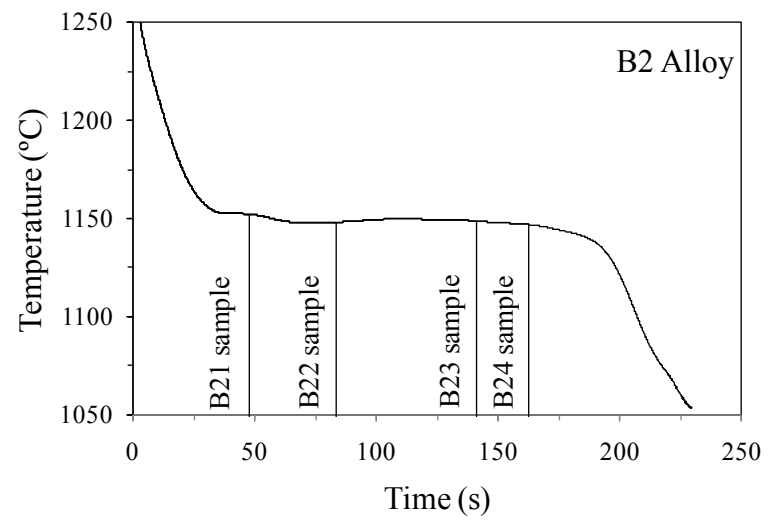

(d)

Figure 3. Quenching experiments made for each cast iron alloy. (a) A1 Alloy; (b) B1 Alloy. (c) A2 Alloy; (d) B2 Alloy.

\subsection{Solid Fraction and Graphite Area Fraction Evolution during Solidification}

Quenching experiments performed in such a casting size show some difficulties associated to heat release from the sample. At the same time, the top part is in direct contact with the quenching bath, which assures sufficient cooling rate to succeed in freezing the structure, the bottom part has more difficulty to release the heat and so higher fs are expected in those areas. For this reason, in the same sample, different fs and graphite precipitation can arise from the quenching process. As the main aim of this work was to correlate graphite amount evolution and fs, it was considered convenient to analyze the 12 different fields described in Figure 1. Solid fraction evolutions of both inoculated A and B alloys in field No. 11, i.e., the most sensible to quenching, are shown in Figures 4 and 5 respectively.

Metallographic analyses on inoculated A samples show dendrites growing from the liquid while graphite nodules precipitate close to the austenite-liquid interface. This observation agrees with the hypo-eutectic solidification model showed in Figure 2. In the case of inoculated B alloy, solidification starts with the graphite nodules surrounded by small austenite shells together with some isolated dendrites that also exhibit some nodules in contact with them. These last characteristics are usually found in ductile cast irons with a near eutectic solidification [7]. 


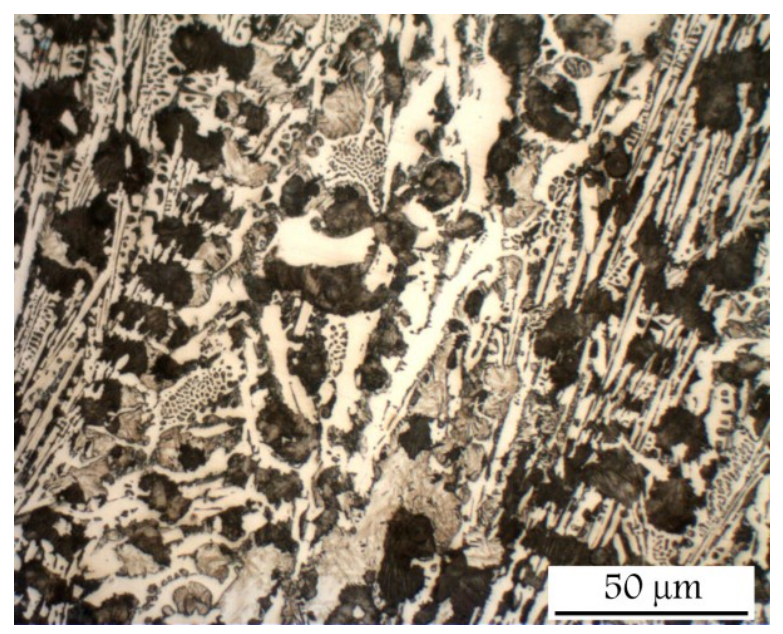

(a)

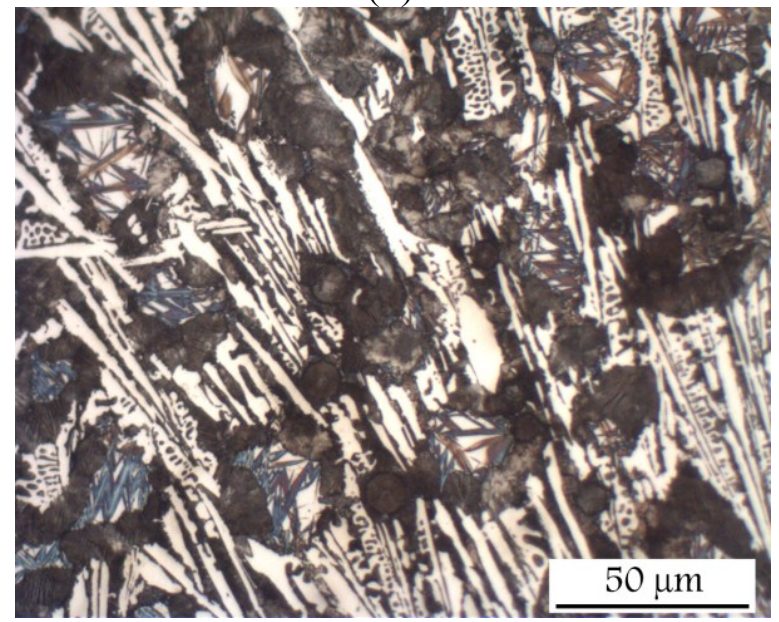

(c)

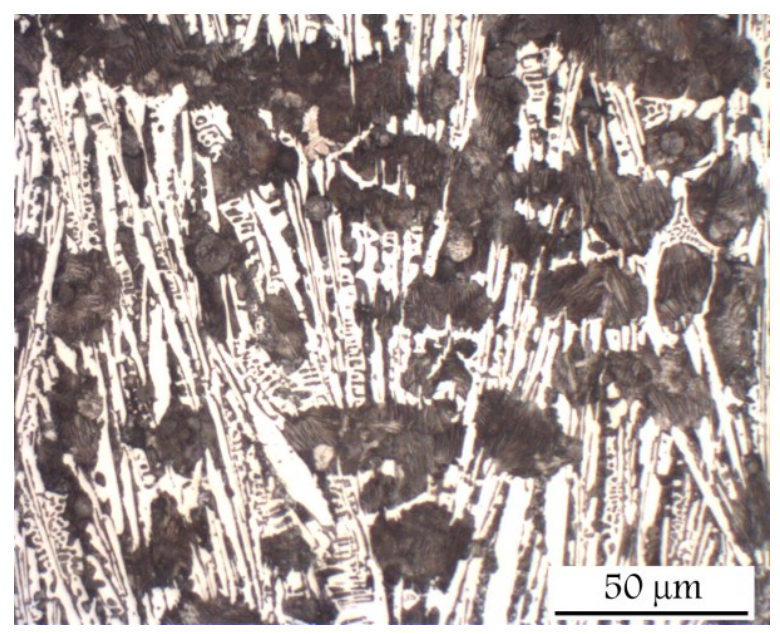

(b)

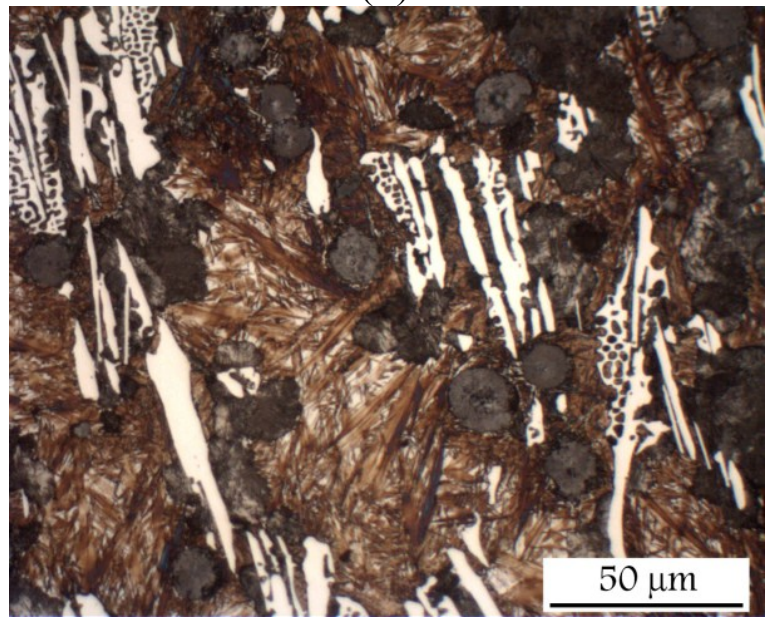

(d)

Figure 4. Solid fraction evolution of A1 samples. (a) A11 Sample; (b) A12 Sample; (c) A13 Sample; (d) A14 Sample.

When comparing A and B alloys higher fs and graphite area fraction ( $\left.f_{\mathrm{GA}}\right)$ values are observed in the later one than in the first one. This result is more evident in case of the more sensitive fields to quenching process, i.e. \#10 to \#12. This behaviour, besides to higher carbon content, must be mainly related to the higher ability to precipitate graphite directly from the liquid in the B alloy which might increase additionally the corresponding austenite precipitation in contact with graphite. Although the non inoculated alloys have shown a similar behaviour to the inoculated ones regarding the effect of $\mathrm{CE}$, inoculation seems to affect more the number of precipitating sites than to fs evolution in the sample fields (Figure 6). It can be observed in this figure that inoculation promotes high nodule counts at the very beginning of the eutectic reaction, which confirms the differences observed in their respective cooling curves. 


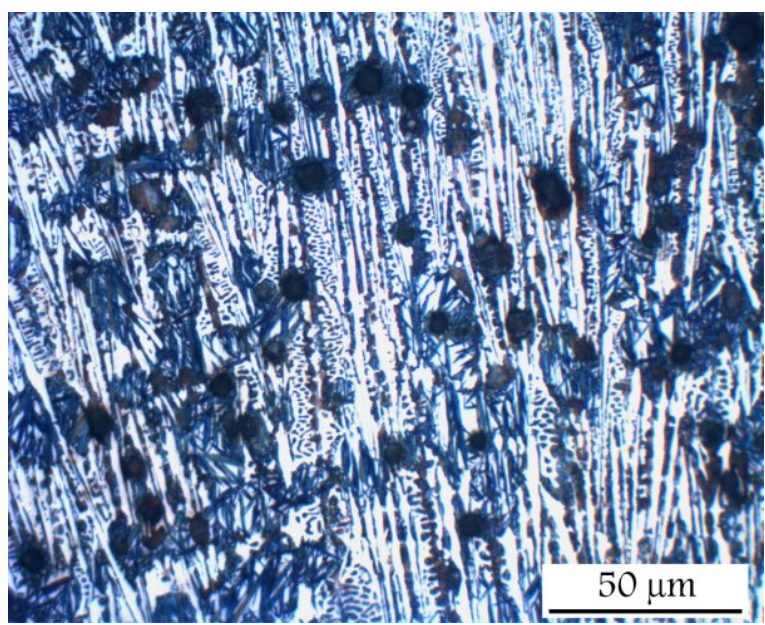

(a)

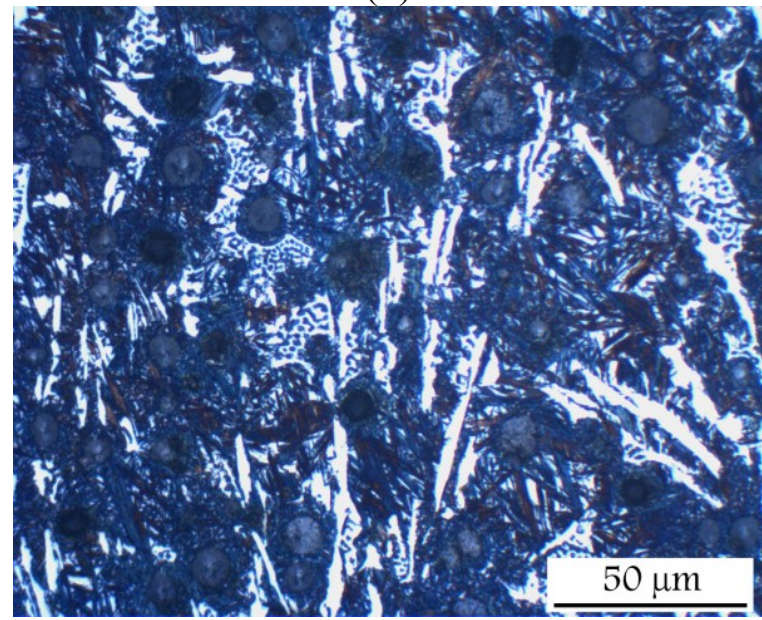

(c)

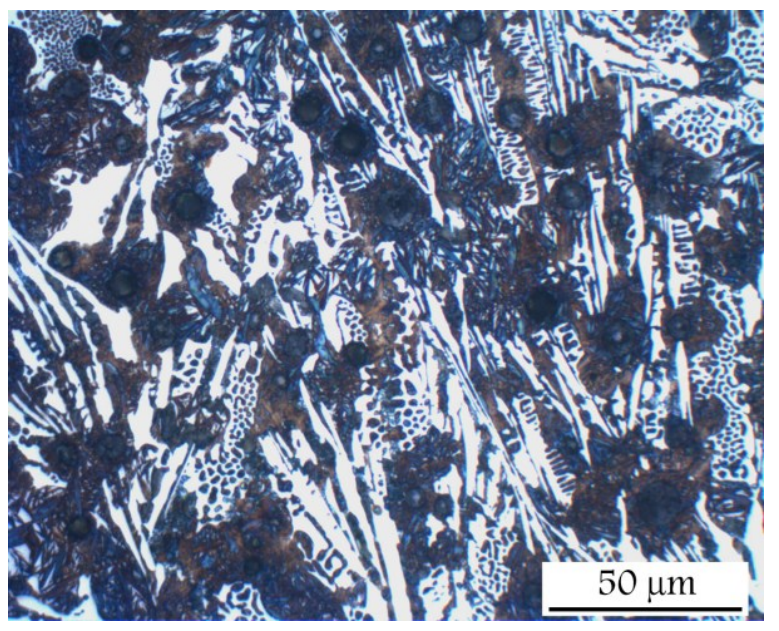

(b)

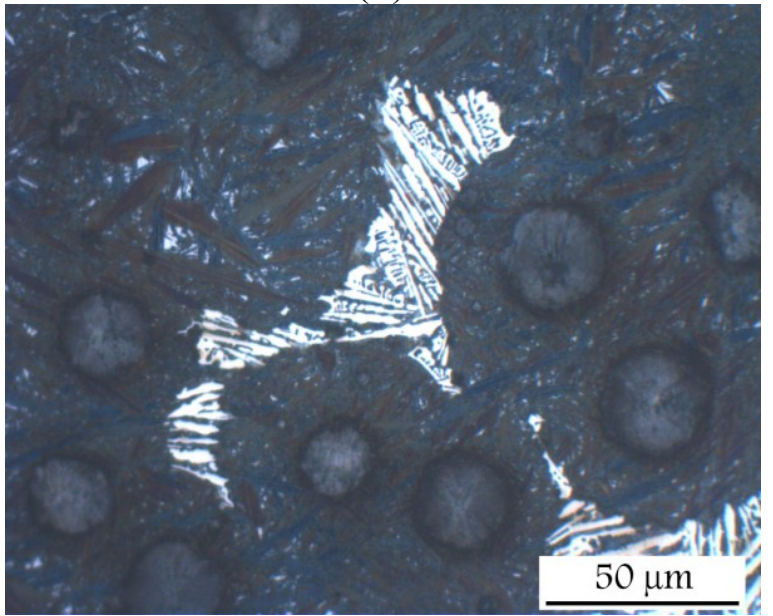

(d)

Figure 5. Solid fraction evolution of B1 samples. (a) B11 Sample; (b) B12 Sample; (c) B13 Sample; (d) B14 Sample.
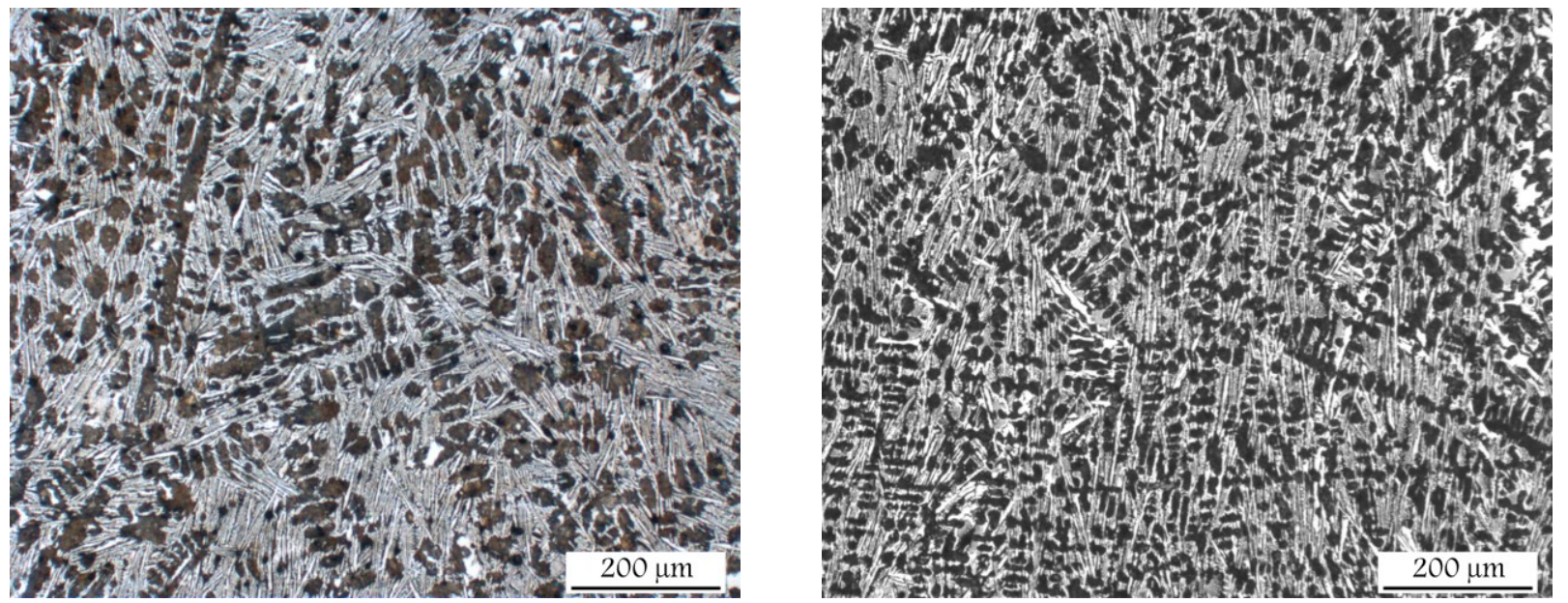

Figure 6. Coarser structure of A alloy in non-inoculated sample (left); compared to the inoculated one (right) for similar solid fraction ( 0.53 and 0.49 respectively).

Surprisingly $f_{\mathrm{GA}}$ values found during solidification of the non-inoculated samples are even higher than those detected on the inoculated ones. This observation can be a consequence of the different 
conception between the number of graphite nodules and their size, i.e., a specific $f_{\mathrm{GA}}$ value can be obtained from both a big number of small nodules and/or from a low amount of big ones. Figure 7 shows an example of such a possibility for two different samples analyzed in the present work. However the graphite area fraction values at the end of solidification become slightly lower in the non-inoculated samples than in the inoculated ones. This result is related to lower nodule count, which enlarges the distances that carbon has to go through by diffusion. Thus a less overall final precipitated graphite amount and a more carbon saturated austenite are obtained for the same solidification time. This effect agrees with the common observation where non-inoculated samples show a higher tendency to shrinkage defect and carbide appearance than inoculated ones for a given composition. Further discussion on this issue will be approached in Chapter 3.3 when studying the nodule count evolution during solidification of the prepared alloys.

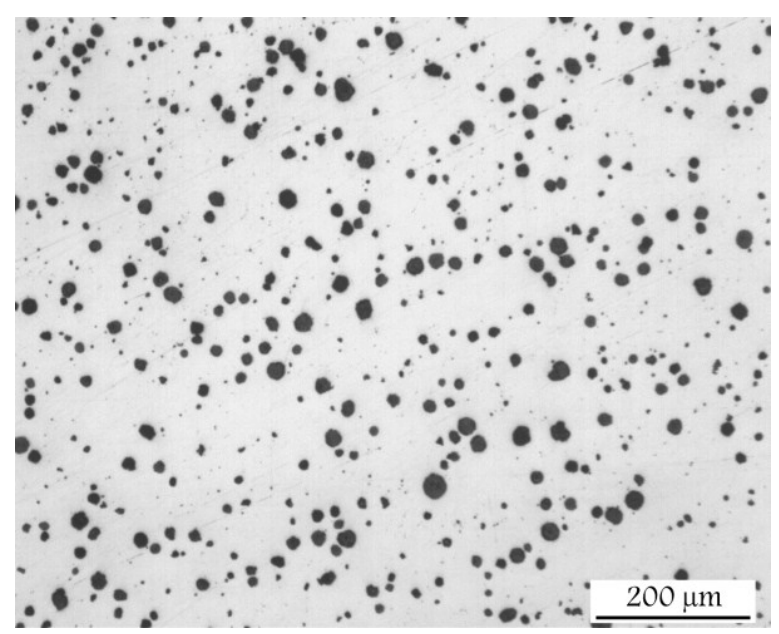

(a)

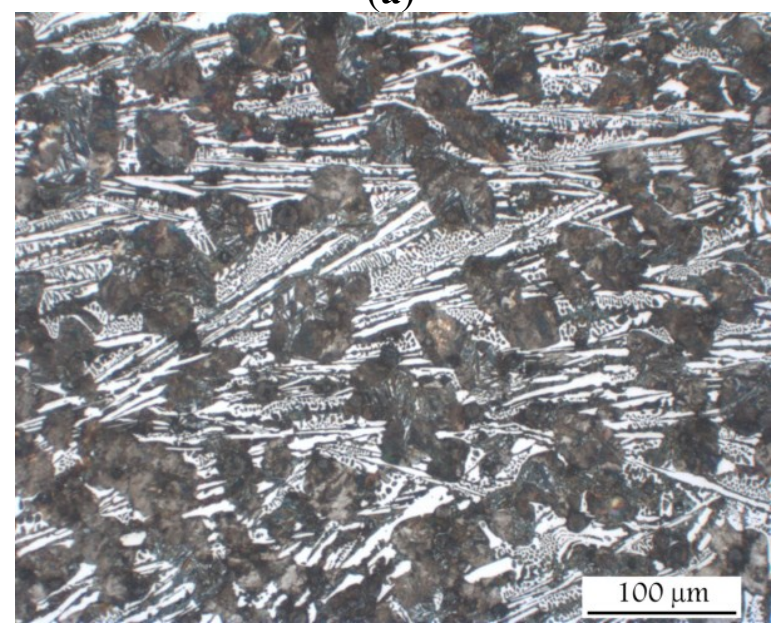

(c)

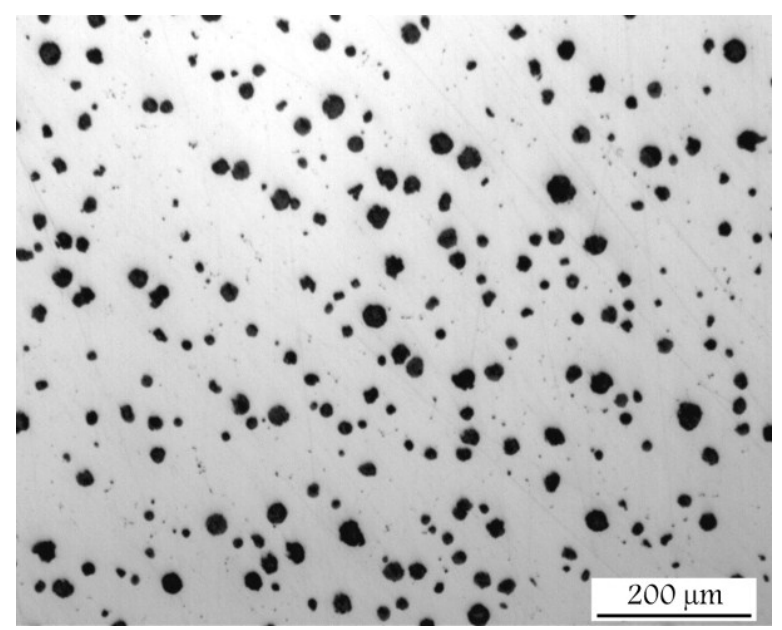

(b)

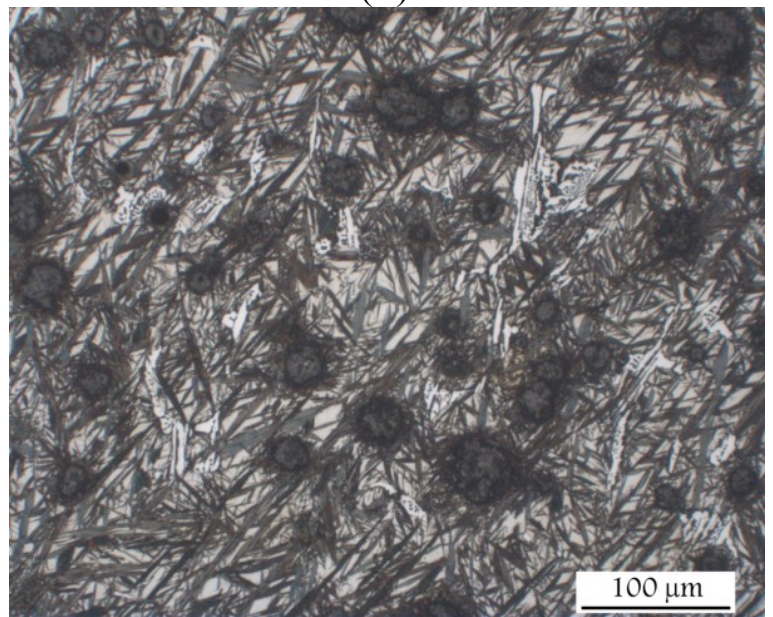

(d)

Figure 7. Different fields for different samples with the same $f_{\mathrm{GA}}$ value $(6.1 \%)$. (a) Field \#5 of A11 sample. $N=527 \mathrm{~mm}^{-2}$; (b) Field \#2 of A23 sample. $N=218 \mathrm{~mm}^{-2}$; (c) Field \#5 of A11 sample. $\mathrm{fs}_{\mathrm{S}}=0.44 ;$ (d) Field \#2 of A23 sample. $\mathrm{fS}=0.90$.

Figure 8 illustrates the correlation between $\mathrm{fs}_{\mathrm{s}}$ and $\mathrm{f}_{\mathrm{GA}}$ for the two inoculated ductile iron alloys. As expected [6] this last parameter increases when solidification progresses (represented here by the means of fs). Scattering of data in the two graphs situated in the top level of Figure 8 is high likely due to 
the different quenching degrees present in each field. Therefore only the most sensitive fields, i.e., \#10 to $\# 12$, were selected for plotting the same correlation (bottom level of Figure 8). This fact is effective for the A alloy samples but it is only partially useful for the B alloy ones probably due to the high graphite nucleation ability present in the latter that stresses the quenching variability. This effect is also supported by the low scattering found in the A2 samples (all metallographic fields considered) when compared to the A1 samples.

Again composition effect on $\mathrm{f}_{\mathrm{GA}}$ is observed here as $\mathrm{B}$ alloy samples lead to the highest values of this parameter (right side of Figure 8). Additionally this increment of the graphite area fraction appears during the whole solidification period and interestingly the primary graphite areas start to form at early fs values for the A alloy case. Thus early graphite nucleation should be expected when increasing CE in ductile iron alloys which must be found when analyzing the nodule count evolution during solidification (see Chapter 3.3). Once again $\mathrm{f}_{\mathrm{GA}}$ evolution during solidification of the non-inoculated samples can be estimated as comparable to the inoculated ones but with lower scattering.

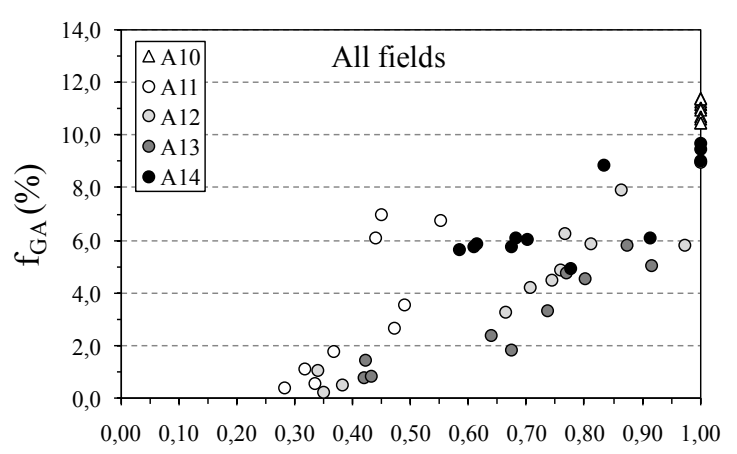

$\mathrm{f}_{\mathrm{S}}$

(a)

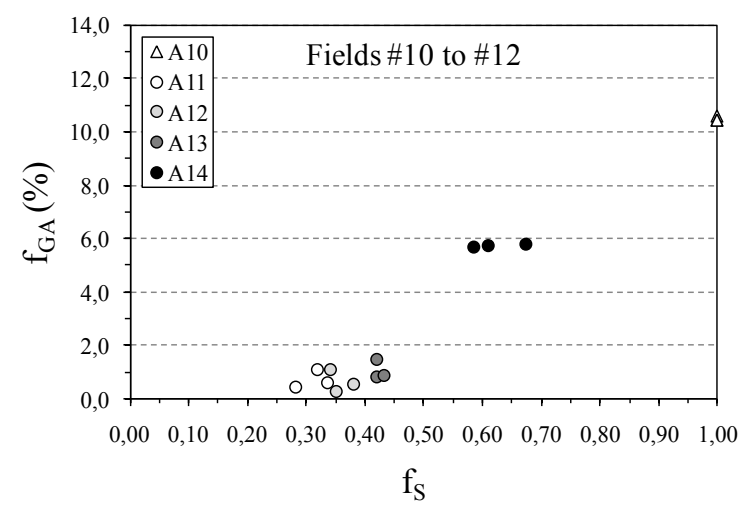

(c)

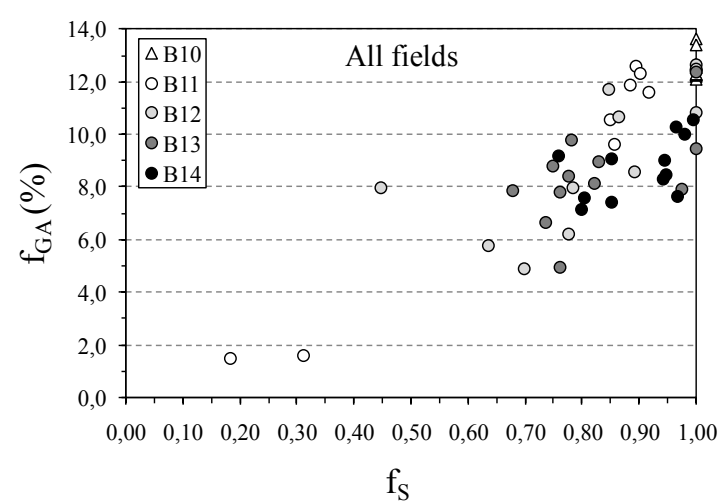

(b)

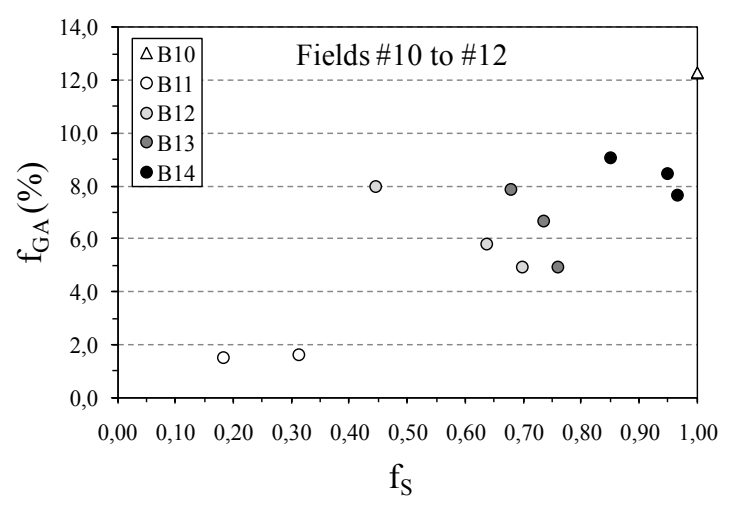

(d)

Figure 8. fs $v s$. f $\mathrm{GA}_{\mathrm{A}}$ correlations for the two inoculated cast irons. (a) all fields for A1 series; (b) all fields for B1 series; (c) Fields \#10 to \#12 for A1 series; (d) Fields \#10 to \#12 for B1 series. 


\subsection{Nodule Count Evolution during Solidification}

Basically, it seems to be worthwhile here to determine comparatively the constituents present in the most sensitive fields when quenching (\#10 to \#12) where fs values are the lowest. Table 3 shows the fs, $\mathrm{f}_{\mathrm{GA}}$, and $N$ average values distributed by size. B21 is not considered due to pearlite appearance as mentioned above.

Table 3. Solid fraction and nodule count average values around the liquidus arrest in fields $\# 10$ to $\# 12$.

\begin{tabular}{cccc}
\hline Sample & $\mathbf{f S}_{\mathbf{S}}$ & $\mathbf{f}_{\text {GA }}(\mathbf{\%})$ & $\boldsymbol{N}<\mathbf{0 . 0 1 5} \mathbf{~ m m}\left(\mathbf{m m}^{-\mathbf{2}}\right)$ \\
\hline A11 & 0.31 & 0.7 & 146 \\
A21 & 0.33 & 0.8 & 163 \\
B11 & 0.25 & 1.6 & 344 \\
\hline
\end{tabular}

As expected in this early step of solidification both intermediate- and big-sized graphite nodules were not found. Thus the $\mathrm{f}_{\mathrm{GA}}$ values included in Table 3 only correspond to the small range of nodules. The comparative analysis of data shows the composition effect on the liquidus reaction, i.e., both $\mathrm{f}_{\mathrm{GA}}$ and $N$ are much higher for the B11 sample than for the A11 one (both alloys are inoculated) even though fs is higher in the last case than in the former one. Thus graphite nucleation is strongly favored by increasing CE.

However a comparison between A11 and A21 samples leads to the idea that the inoculation effect is not the expected one at the beginning of the solidification. Data obtained from the most sensitive part of these two samples indicate that quite similar $\mathrm{f}_{\mathrm{GA}}$ and $N$ values are obtained when adding inoculant to the A alloy. This result is different to the effect found in a previous work [7] where a near eutectic ductile iron alloy increased the nodule count (from 40-67 mm $\mathrm{mm}^{-2}$ ) at the beginning of the liquidus arrest ( $\left.\mathrm{fs}_{\mathrm{S}}=0.06\right)$ when adding inoculant. A possible reason for this lack of agreement could be the quite lower $\mathrm{Te}_{\min }$ value of such non inoculated alloy $\left(1133.3^{\circ} \mathrm{C}\right)$ in contrast to alloy $\mathrm{A} 2\left(1140.9^{\circ} \mathrm{C}\right)$ as this parameter has been successfully related to the graphite nucleation potential of solidifying melts [2]. Unfortunately the B21 sample was discarded in this work so this item will now be a subject for further investigations.

Quenching variability on the different fields of samples was studied in the previous chapters so it is interesting to approach a similar analysis here. Apart from the graphite nucleation potential exhibited by melts, nodule count is affected by cooling conditions. Thus $N$ parameter can be increased by accelerating the cooling process. However it will become very low if the cooling rate is too fast as in quenching experiments. In spite of admitting that some nucleation and growth may occur due to the quenching method, it must be taken into account that the time for this to happen is limited, so the final graphite amount is the sum of both effects. In any case, the obtained results should be considered as comparable in order to determine the effect of the chemical composition and inoculation process.

It was observed in this work that the distribution of nodule count strongly depends on nodule size. A comparison between the three different nodule sizes found in this work is illustrated in Figure 9 where the two inoculated ductile iron alloys only are included. Thus the central fields (\#4 to \#9) contain the highest small nodule count during solidification while the bottom part of the samples (fields \#1 to \#3) shows the highest amount of nodules $0.015-0.030 \mathrm{~mm}$ and $0.030-0.060 \mathrm{~mm}$ in size. Note also that $N$ 
values at the end of solidification are quite low for the smallest size $\left(50-60 \mathrm{~mm}^{-2}\right)$ while they almost achieve the maximum value of the two other big sizes.

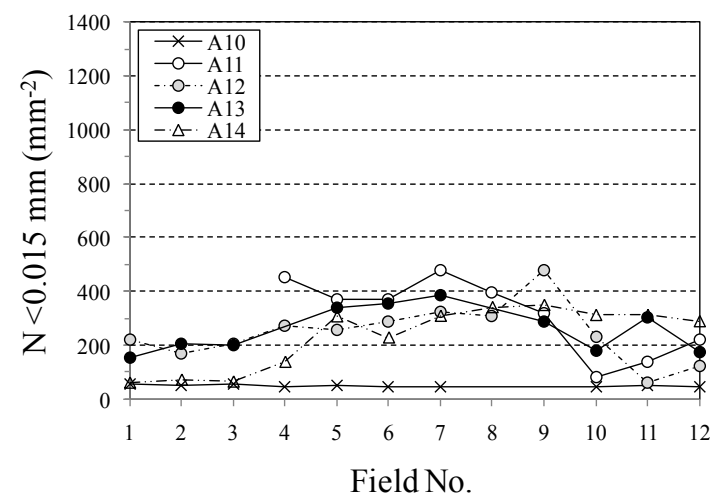

(a)

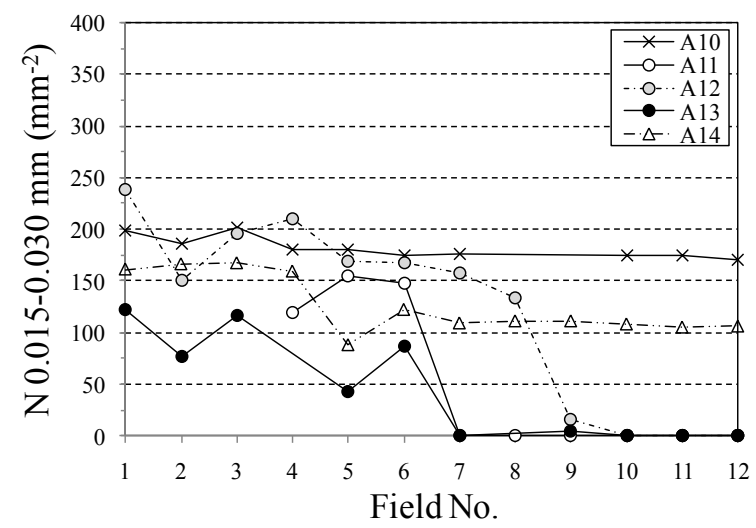

(c)

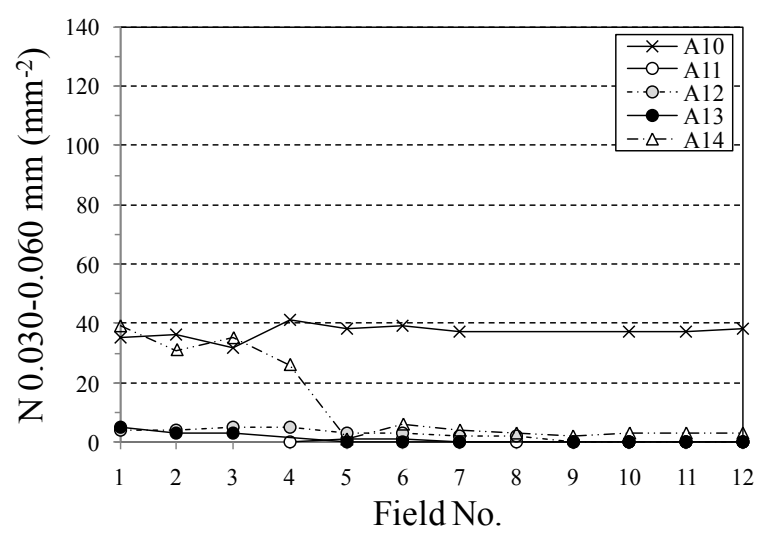

(e)

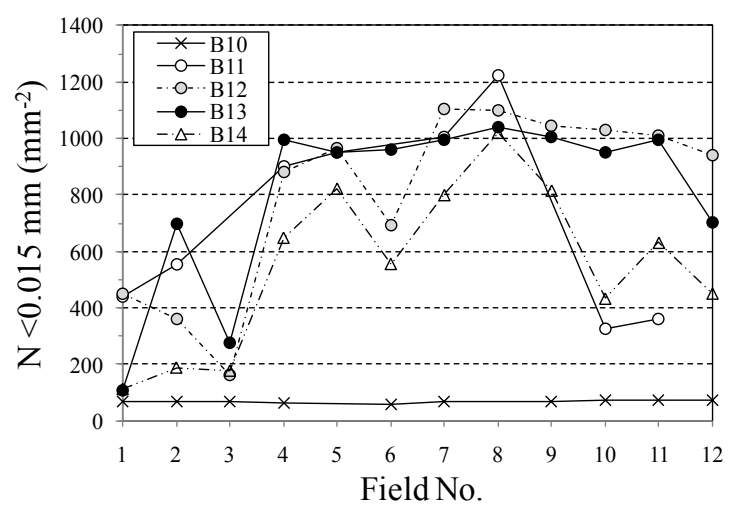

(b)

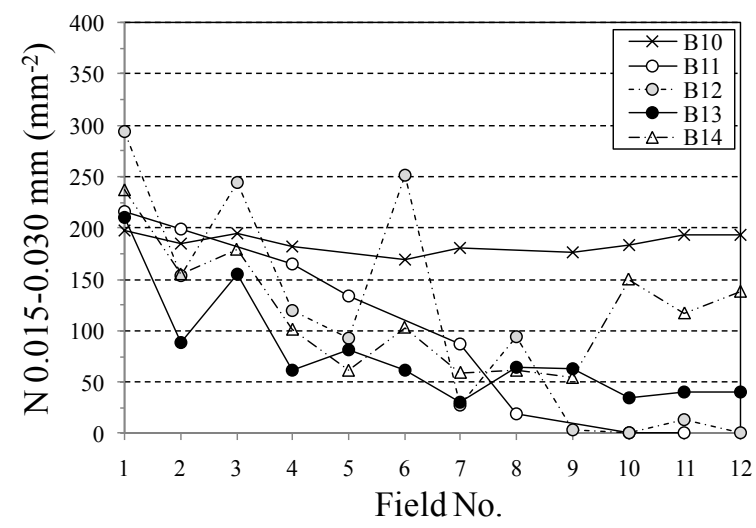

(d)

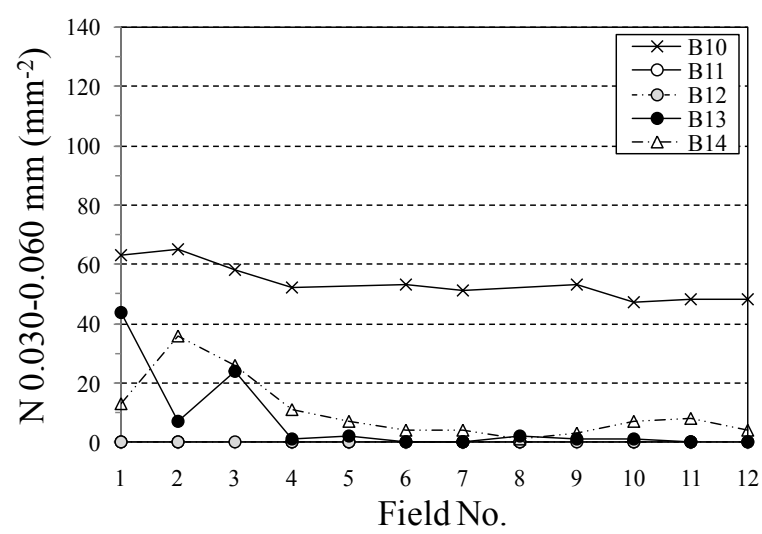

(f)

Figure 9. Nodule count distribution in all fields for the inoculated samples. (a) Nodule count for the smallest nodule size $(<0.015 \mathrm{~mm}$ ) of A1 series; (b) Nodule count for the smallest nodule size $(<0.015 \mathrm{~mm})$ of B1 series; (c) Nodule count for the nodule size $0.015-0.030 \mathrm{~mm}$ of A1 series; (d) Nodule count for the nodule size 0.015-0.030 mm of B1 series; (e) Nodule count for the nodule size $0.030-0.060 \mathrm{~mm}$ of A1 series; (f) Nodule count for the nodule size $0.030-0.060 \mathrm{~mm}$ of B1 series.

When avoiding inoculation on samples included in Figure 9, nodule count values during solidification become significantly lower than in the inoculated samples. However the affected fields and the shape of 
such distributions are quite similar to the inoculated cases. After completing the solidification period the non-inoculated samples also show a very low nodule count for the smallest nodule size (similar to the one detected for the inoculated samples) but $N$ is significantly lower for the two other sizes when compared to the corresponding inoculated samples.

In order to see the evolution of the different nodule sizes during the solidification in a more proper way, it seems to be necessary to include the fs parameter in this chapter. Figure 10 illustrates these $N$ evolutions for both the A1 alloy and the B1 one (only the smallest nodule size distribution has been included in the last alloy for comparison). As it has been previously stated the smallest graphite nodules apparently start to form from the liquid alloy in the very early solidification steps $\left(f_{S}=0.05-0.20\right)$ as it was previously reported $[6,8,12]$. Then a maximum $N$ value is reached in the $0.50-0.70$ solid fraction range for the A1 samples while this range becomes $0.50-0.80$ for the $\mathrm{B} 1$ ones. Finally $N$ values decrease at the end of liquid-solid transformation. On the other hand the two big nodule sizes show an increasing evolution during the solidification process (see right side plots in Figure 10) until achieving the maximum $N$ value at the end of this transformation. Note that $N$ scales are different in two of the four graphs included in this figure.

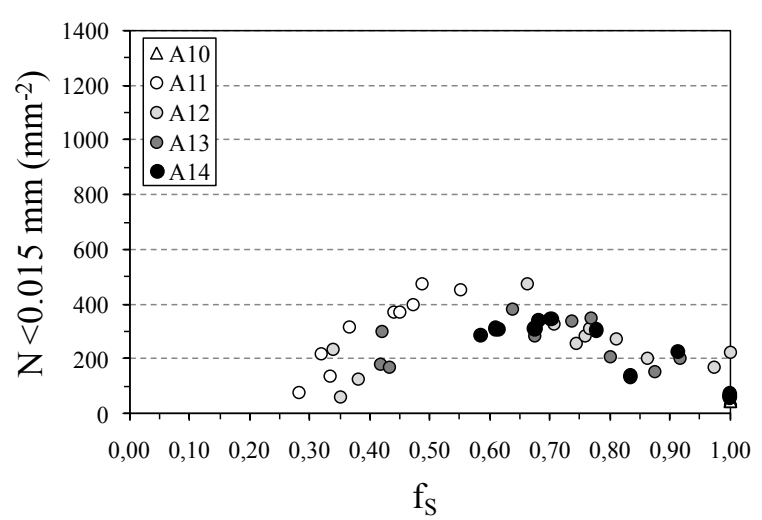

(a)

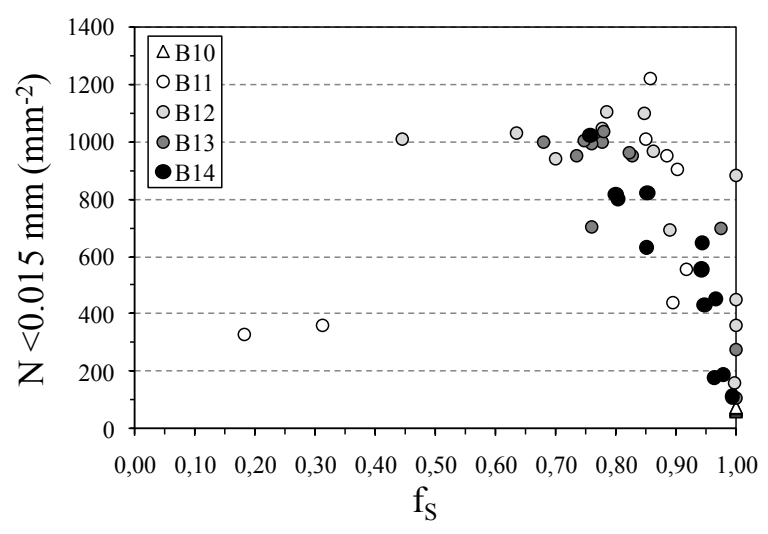

(c)

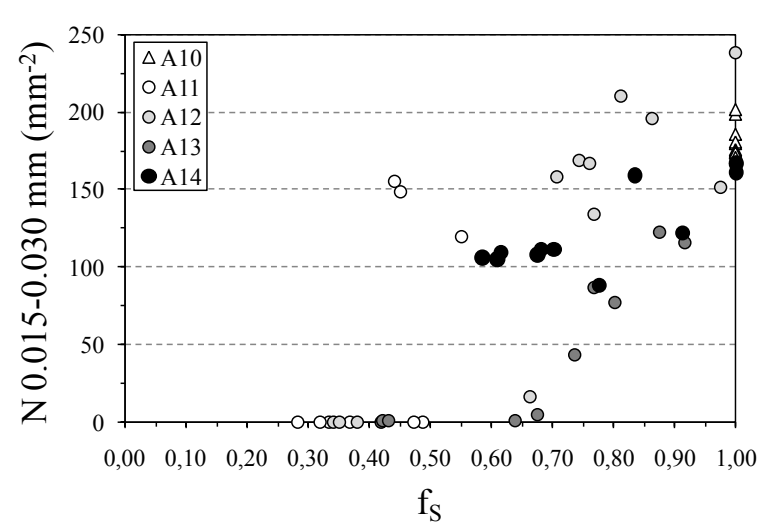

(b)

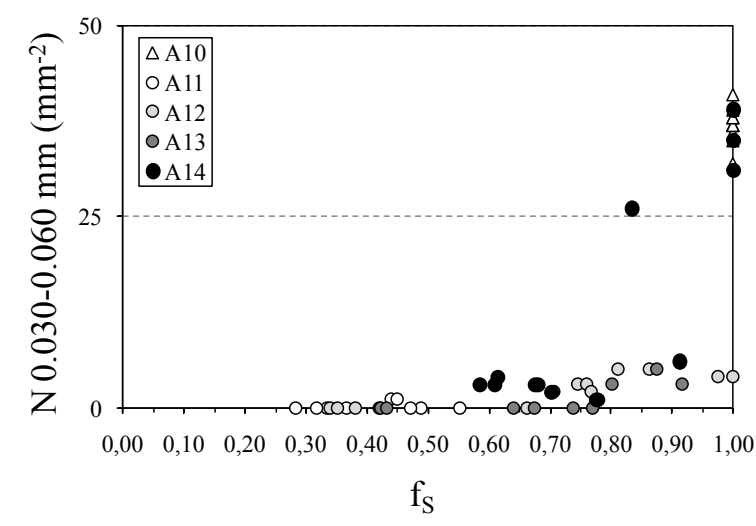

(d)

Figure 10. Nodule count evolution during solidification process (all fields are included). (a) Smallest nodule count evolution $v s$. fs for A1 series; (b) 0.030-0.060 mm nodule count evolution vs. fs for A1 series; (c) Smallest nodule count evolution vs. fs for B1 series; (d) 0.030-0.060 mm nodule count evolution $v s$. fs for A1 series. 
When increasing CE in the alloy it is observed that all $N$ evolution shapes are comparable to the A alloy case though the nodule count values strongly increase (see the two graphs on the left side of Figure 10). Note here, that the smallest nodule count also decreases $\left(50-70 \mathrm{~mm}^{-2}\right)$ at the end of solidification, even for the B alloy samples.

Regarding the inoculation effect on $\mathrm{N}$, no relevant changes on these evolution shapes due to the lack of inoculation have been detected in this study. On the other hand it was confirmed that comparatively minor increments on nodule count values are obtained due to inoculant addition over the whole range of solidification, i.e., the composition effect becomes the most powerful one. However the weak but clear increase of $N$ due to inoculation observed here can be more potent in those alloys that exhibit a low graphite nucleation potential before adding an inoculant, as already detected in a previous work [7]. The most important increment of $N$ due to inoculation affects the graphite nodules $0.030-0.060 \mathrm{~mm}$ in size, i.e., the biggest ones. These nodules are also called "primary nodules" because they nucleate at the very beginning of the solidification. Therefore it is possible to assume that inoculation promotes the early precipitation of graphite particles. This result should support the unusually high graphite nucleation potential of A2 alloy as being the main cause of the apparent negligible inoculation effect on A21 sample with respect to the A11 one (see Table 3).

Correlations between $N$ and $\mathrm{f}_{\mathrm{GA}}$ are similar to those obtained when using the solid fraction as the parameter for analyzing the solidification progression. However scattering of data is high for the first case (especially when analyzing hyper-eutectic samples). This fact should be related to the uncertain balance among $\mathrm{f}_{\mathrm{GA}}$, nodule count and the size of nodules as was mentioned in Chapter 3.2.

Figure 11 shows the evolution of total nodule count values obtained from the quenched samples and from the non-quenched one for all ductile irons prepared in this work. The downward evolutions found in the two B alloys are a consequence of the observed strong contribution coming from the small-sized graphite nodule evolution during solidification. On the contrary A alloys show much more stable tendencies though they can also be considered as descending ones.

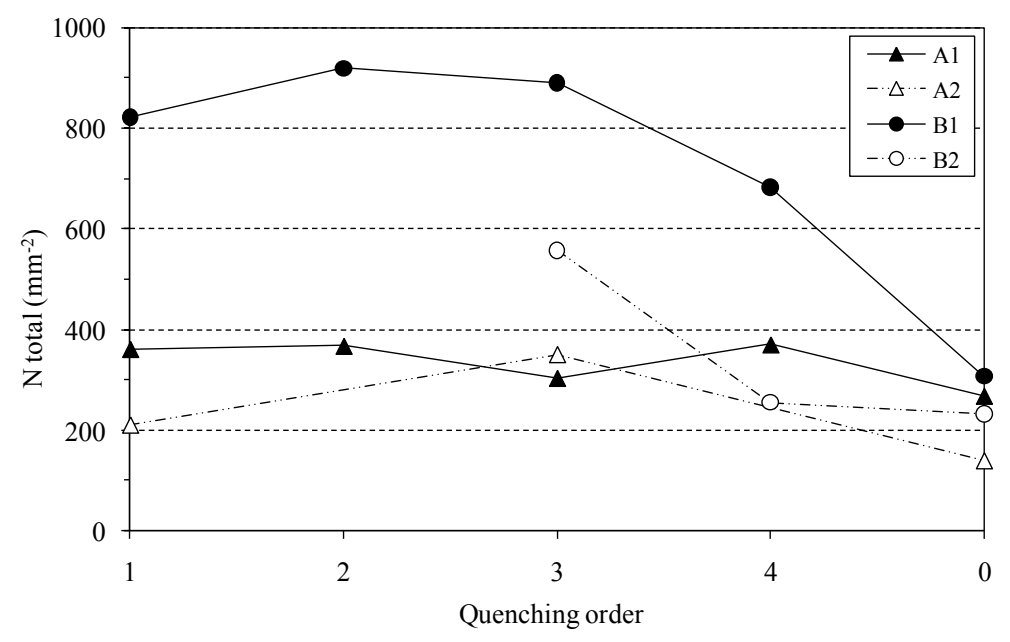

Figure 11. Total nodule count evolution with all quenched samples.

It has been already stated up to now that an increase of the graphite area fraction at the end of solidification is obtained when increasing the CE content of the alloy (see Figure 8). However this result has to be combined with two other observed phenomena: an important reduction of the smallest nodule 
count and an increase of the big-sized nodules. Two different explanations were considered in the present work to tackle this difficulty. One of them pre-supposes that the smallest-sized graphite nodules mainly found in the central areas of samples with maximum nodule count values, detected in $\mathrm{fs}_{\mathrm{S}}=0.50-0.80$, are formed due to the quenching process. Thus these observations must not be found when samples solidify under normal cooling conditions. It is assumed that some undercooling can be expected before freezing the resulting matrix structure due to quenching. Thus the alloy in contact with the quenching media should freeze almost immediately so very low extra undercooling would be expected on it. Thus the former solidified layer makes the heat release from the inner zones more difficult in such a case, slowing down the very high cooling rate expected from quenching, and slightly increasing undercooling before the quenching effect reaches these internal zones. Such phenomena would lead to obtaining sufficient time for small graphite particles to be precipitated. This effect would be more noticeable on increasing the distance from the quenching media and would explain the fs and nodule count distributions showed in the top level of Figure 9. According to this explanation, the quenching methodology used in the present study would change the observed solidification development although, at the same time, it would mean that the conditions to form these phases already existed at this particular time.

Another way to explain the small-sized nodule count evolution during solidification is to assume that the quenching process is fully effective although some cooling variability is present in the whole of the samples. Thus a true precipitation of small graphite nodules would occur in the way shown in Figures 9 and 10. This fact means that some of the nodules do not achieve the required size that would allow further growth on the nodules, so they become less stable and disappear. According to this assumption, coarse graphite nodules would grow by carbon diffusion, also coming from these small graphite nodules which would be disappearing during the last period of the solidification process. Furthermore, it implies that not every nodule is formed at the very beginning of the solidification but rather nucleation development occurs during all the transitions. The high smallest nodule count values found in the center of the fields of many samples, with a solid fraction in the range $0.70-1.00$, could be explained by means of this second postulation.

From a general point of view high CE contents would lead to formation of a huge amount of small-sized graphite nodules. Some of them nucleate and grow from the liquid by carbon atom buildup, meanwhile others grow probably by accepting carbon atoms which come from other nodules by diffusion. Thus these last nodules would progressively disappear and the total nodule count would decrease during solidification until achieving the final value once fs becomes 1.00. Inoculation would show a similar effect to the one described for CE.

Unfortunately neither of these two possible explanations was verified in the present work and therefore will be approached in further investigations. However quenching experiments must be useful for comparing the different results obtained when varying processing parameters as $\mathrm{CE}$ and inoculation. Thus the downward trends found in all four alloys (Figure 11) contrast with some others previously reported in the literature for ductile irons [7]. In such a work FGE1i denotes a hyper-eutectic and inoculated alloy that showed a similar trend to the one found for B1 alloy (Figure 11). In the same study the nodule count evolutions for FGE1ni (hyper-eutectic and non-inoculated alloy), FGE2i, and FGE2ni (both near eutectic alloys which are inoculated and non-inoculated respectively) are, however, upward while the opposite trends are found for the B2, A1, and A2 alloys. 
These different behaviors mean that another important aspect is acting on $N$ evolution in addition to $\mathrm{CE}$ and inoculation. Once again the graphite nucleation potential of melts should play an important role in this way. In fact the $T \mathrm{e}_{\min }$ values for FGE2i $\left(1144.8^{\circ} \mathrm{C}\right)$ and for FGE2ni $\left(1133.3{ }^{\circ} \mathrm{C}\right)$ alloys are lower than the ones obtained for A1 and A2 (see Table 2). Thus a high nucleation potential would also increase the obtained number of graphite nodules at the beginning of solidification and tendencies like the ones plotted in Figure 11 become downward for a given CE and inoculation condition. The authors already correlated this aspect with $N$ and the shrinkage tendency of ductile irons [2] although only final nodule count values were considered in this previous work.

\section{Conclusions}

The following conclusions can be drawn from the present work:

1. Small nodules rapidly form at the beginning of solidification. As the solidification advances medium-sized graphite nodules together with the maximum amount of the smallest nodules are achieved. When $\mathrm{fs}_{\mathrm{S}}$ is higher than 0.8 , medium- and big-sized nodules become predominant while the amount of the smallest ones decreases until reaching a minimum value at the end of the solidification.

2. $\mathrm{CE}$ and inoculation promote the increase of graphite size during the solidification process. In the present study, CE was shown to be a more influential parameter than inoculation. Notwithstanding, the biggest graphite nodules are observed in low CE alloys.

3. Inoculation increases the final precipitated graphite content.

4. As CE increases, nodule count shows a tendency to decrease with fs while low CE maintains a fairly similar nodule count during the whole solidification process in the present study. These tendencies were not found in a previous work already published by the authors. A comparative analysis of the thermal records in the two works shows that this disparity may be related to the graphite precipitation ability of the melt, i.e., the amount of seeds where graphite can nucleate.

\section{Acknowledgments}

The authors acknowledge Basque Government for the funding received in its "Ikertu" program. The authors would like to thank Technology Quality Control, S.L.U. for all the collaborating efforts made in the experimental tests.

\section{Author Contributions}

All the authors contributed equally to the present work. A.N. designed and performed experiments and collected data; R.S. designed experiments and gave technical support and conceptual advice; J.S. designed experiments, analyzed data and wrote the paper; P.L. designed experiments, analyzed data and wrote the paper; All authors discussed the results and implications and commented on the manuscript at all stages.

\section{Conflicts of Interest}

The authors declare no conflict of interest. 


\section{References}

1. Stefanescu, D.M. Solidification and modeling of cast iron-A short history of the defining moments. Mater. Sci. Eng. A 2005, 413-414, 322-333.

2. Larrañaga, P.; Gutiérrez, J.M.; Loizaga, A.; Sertucha, J.; Suárez, R. A computer-aided system for melt quality and shrinkage propensity evaluation based on the solidification process of ductile iron. AFS Trans. 2008, 116, 547-561.

3. Oldfield, W. A quantitative approach to casting solidification: Freezing of cast iron. Trans. ASM 1966, 59, 945-961.

4. Lora, R.; Diószegi, A.; Elmquist, L. Solidification study of gray cast iron in a resistance furnace. Key Eng. Mater. 2011, 457, 108-113.

5. Guo, X.; Stefanescu, D.M. Solid phase transformation in ductile iron. AFS Trans. 1997, 105, 533-543.

6. Mampaey, F. Quantitative description of solidification morphology of lamellar and spheroidal graphite cast iron. AFS Trans. 1999, 107, 425-432.

7. Larrañaga, P.; Sertucha, J.; Suárez, R. Análisis del proceso de solidificación en fundiciones grafíticas esferoidales. Revista de Metalurgia 2006, 42, 244-255.

8. Boeri, R.E. The Solidification of Ductile Cast Iron. Doctoral Thesis, Faculty of Graduate Studies, Department of Metals and Materials Engineering, The University of British Columbia, Vancouver, BC, Canada, November 1989.

9. Liu, Y.; Yang, S. Growth mode and modification of graphite in cast iron melt. Acta Metall. Sinica 1992, 5, 263-267.

10. Alonso, G.; Stefanescu, D.M.; Larrañaga, P.; Suárez, R. Understanding compact graphite iron solidification through interrupted solidification experiments. In Proceedings of the 10th International Symposium on the Science and Processing of Cast Iron (SPCI-10), Mar de Plata, Argentina, 10-13 November 2014.

11. Fidos, H. A study of the graphite morphology in nodular cast iron. FWP J. 1977, 17, 39-54.

12. Lacaze, J.; Castro, M.; Aichoun, N.; Lesoult, G. Influence de la vitesse de refroidissement sur la microstructure et la cinétique de solidification de fontes G.S.: Expérience et simulation numérique de solidification dirigée. Mémoires et Etudes Scientifiques Revue de Métallurgie 1989, 2, 85-97.

13. Larrañaga, P.; Sertucha, J. Estudio térmico y estructural del proceso de solidificación de fundiciones de hierro con grafito laminar. Revista de Metalurgia 2010, 46, 370-380.

(C) 2015 by the authors; licensee MDPI, Basel, Switzerland. This article is an open access article distributed under the terms and conditions of the Creative Commons Attribution license (http://creativecommons.org/licenses/by/4.0/). 